\title{
China's Natural Gas Price Reform and Its Impact Analysis
}

\author{
Li Zhao ${ }^{1, a}$, Yu Lulu ${ }^{2, b^{*}}$ \\ ${ }^{1}$ Department of Economics in Xi'an Mingde Institute of Technology, Xi'an, Shaanxi, China \\ ${ }^{2}$ Department of Economics in Xi'an Mingde Institute of Technology, Xi'an, Shaanxi, China
}

\begin{abstract}
With the further development of new types of industrialization and urbanization in China, the environmental deterioration and energy safety problems have been increasingly prominent. As a clean, efficient and high-quality energy source, natural gas has ushered in unprecedented development opportunities. In recent decades, the natural gas consumption has kept high-speed growth in China, but its proportion in the energy consumption structure still has a long way to go to reach the international average level, which is mainly ascribed to the not perfect enough market-oriented reform of natural gas price. Natural gas price reform is not a simple project, but instead, it is complicated as it needs to integrate the reform in the natural gas industry chain, management system reform and market supervision of natural price in different phases. Therefore, promoting the natural gas price reform and establishing a perfect supervision system is the only way to ensure China's energy safety and realize the transformation and development of low-carbon economy. In this research, the current situation and problems existing in the natural gas price reform in China were analyzed, and the concrete solutions specific to the natural gas industry chain, pricing and market supervision .
\end{abstract}

\section{Introduction}

In the development phase with accelerated industrialization and urbanization, the energy safety problem and environmental deterioration problem, etc. have been increasingly prominent due to the everincreasing energy needs in China. During the sensitive period featured by the pursuit of low-carbon economic development and great transformation of energy environment, natural gas has become a high-quality alternative energy source by virtue of high efficiency, cleanness, low carbon, environmentally friendly nature, etc. In China, the natural gas consumption reached 308 billion cubic meters by the end of 2019 , accounting for $8.1 \%$ in the primary energy consumption structure, and the consumption quantity presented steady growth. As the goals with respect to peak carbon dioxide emissions and carbon neutral are proposed in China, and the shale gas revolution is initiated in America, natural gas, an important member in the optimized energy structure, will become a great force propelling the energy production and consumption revolution and building a modern clean, safe and efficient low-carbon energy system in China. Nevertheless, the proportion of natural gas in China's energy consumption structure lags far behind the world average level due to imperfect market development and unreasonable pricing mechanism of natural gas in China, so the natural gas price reform becomes imperative.

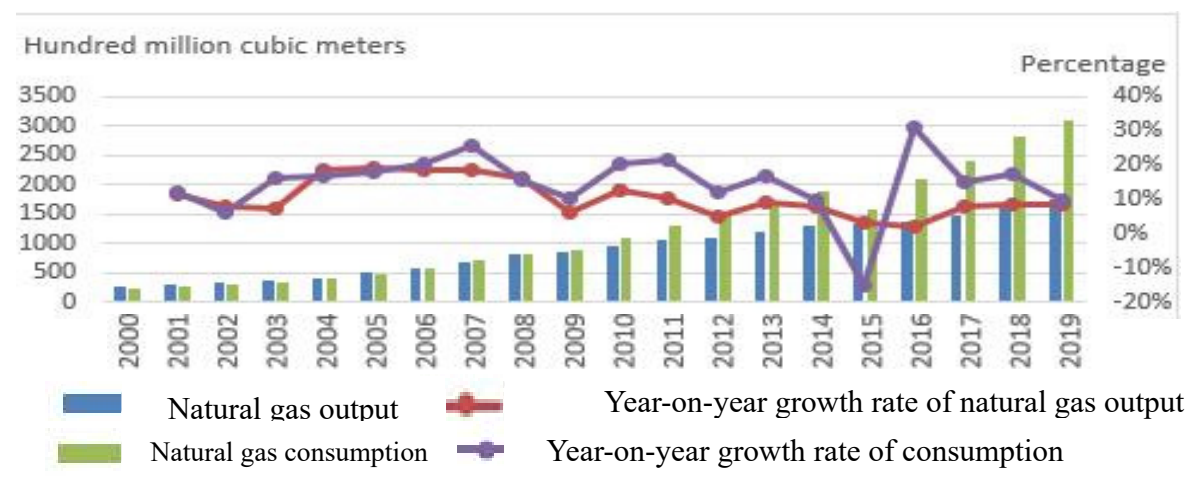

Figure 1. Output, Consumption Quantity and Year-on-Year Growth Rate of Natural Gas During 2000-2019 (unit: hundred million cubic meters, \%

\footnotetext{
a nwpulizhao@163.com

b*yll@mdit.edu.cn
} 


\section{Literature Review}

The natural gas price reform has always aroused high attention from both domestic (Chinese) and foreign scholars. For instance, Sergey Paltsev ${ }^{1}$ pointed out that China's natural gas price was always put under surveillance, while the old pricing mechanism failed to effectively motivate natural gas suppliers, thus leading to the shortage of natural gas supply. Aviral Kumar ${ }^{2}$ Tiwari et al. found that both natural gas price and crude oil price were pro-cyclical, and moreover, they were highly correlated. Based on the development and utilization status of natural gas resources in China, Lin $\mathrm{L}^{5}$ analyzed the pilot reforms in Guangdong Province and Guangxi Zhuang Autonomous Region, and found that the natural gas price reform, to a certain extent, strengthened the longterm response of domestic industrial natural gas price to internal crude oil price. Affected by intricate factors such as economic, political and social factors, it has been a consensus and development direction in the global oil and gas industry to establish a clean, safe and efficient lowcarbon energy system. As stated by Chen $\mathrm{B}^{4}$ (2018), the market could play a significant role in the resource allocation only by facilitating the natural gas price reform. Combining the status of the natural gas industry with countries processing relatively complete international natural gas markets, Zhao $\mathrm{H}$ analyzed the pricing patterns and development courses of natural gas industry in typical countries such as America, Russia and Britain, and proposed the policy orientation suitable for the natural gas price reform in China, which would be of certain reference significance for the city gas industry and enterprises within the industry to cope with the price reform in progress.

\section{Current Situation of China's Natural Gas Market}

\subsection{Current situation of natural gas industry chain}

The natural gas industry chain can be largely divided into three links: upstream exploration and development, midstream pipeline transportation and downstream distribution and sales, and the price in the natural gas industry chain is composed of ex-factory price (upstream link), pipeline transportation price (midstream link) and gas distribution price (downstream link). The structural optimization of natural gas industry chain is inseparable from the natural gas price reform, because the price can be correctly reflected only by a benign and complete industrial chain.

From the angle of industrial chain, the upstream link mainly takes charge of natural gas exploration and development. To encourage natural gas production and guarantee the supply, the right of natural gas exploration and development was transferred by means of registration in early phase, so three giant companies - CNPC, Sinopec and $\mathrm{CNOOC}$ - possessed the vast majority of the right of exploration and development by prior registration. Now this right is mainly mastered by four enterprises: CNPC, Sinopec, CNOOC and Shaanxi Yanchang Petroleum, among which CNPC accounts for as high as $75 \%$. In the first three enterprises, CNOOC mainly takes over the exclusive right of offshore oil, while the exclusive right of onshore oil is in the hand of the other two.

The pipeline transportation and storage of natural gas are implemented mainly in the midstream link, which is now highly monopolized. By the end of 2016, the longdistance pipelines of CNPC, Sinopec and CNOOC were about $5.96 \times 104 \mathrm{~km}(88 \%), 0.95 \times 104 \mathrm{~km}(11 \%)$ and 900 $\mathrm{km}(1 \%)$, respectively. As shown in Figure 1, up to the end of 2018, the oil and gas pipeline transportation mileage reached about $122,300 \mathrm{~km}$, which was increased by $25 \%$ in comparison with that in 2012, with a year-on-year growth rate of $2.51 \%$. In 2016, two "measures" were promulgated in China, expecting to separate the pipeline transportation from sales of natural gas. In the end of 2016, CNPC and Guanghui Energy signed a tri-party pipeline access agreement, however, there is still in shortage of impetus.

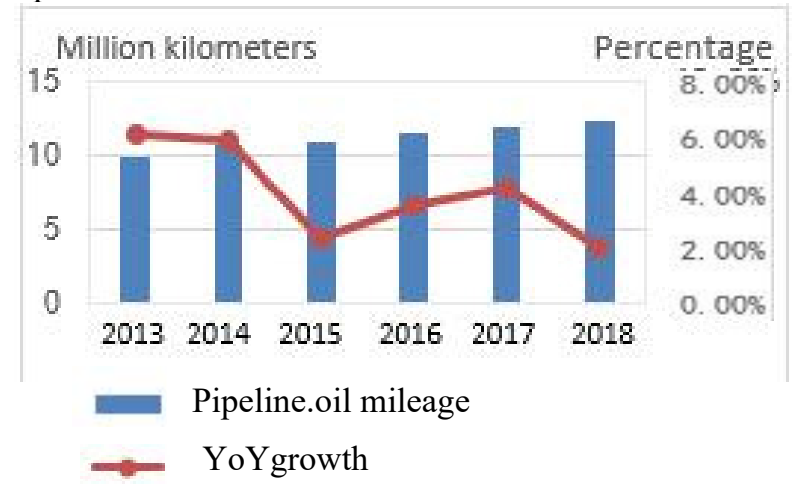

Figure 2. Oil and Gas Pipeline Transportation Mileages in China During 2013-2018 (unit: ten thousand kilometers, \%)

Natural gas is distributed mainly in the downstream link, namely, the long-distance pipeline transported gas in the midstream link is distributed to end users. It has been pointed out by some scholars that although the rates of return on sales of Kunlun Energy, CR Gas, China Gas and Xinao Gas all exceed 10, belonging to a high barrier level, the weighted average of overall rate of return on sales is only $2.64 \%$ in the downstream link, belonging to medium barrier level, so the competitiveness remains to be further enhanced.

\subsection{Current situation of natural gas pricing}

The cost-plus method had been used in China before 2005, namely, the ex-factory price of natural gas was nationally determined or determined under the national guidance, and the ex-factory price plus the expense in each phase was the price for end users. The cost-plus method played a significant role in protecting the domestic natural gas industry, preventing natural monopoly and encouraging the industrial and residential gas use, etc. during the initial period, in which, however, the gas price was controlled by the government and underestimated somehow, resulting in the distortion of price signals, so the messages could not 
be accurately transmitted to the market. That the gas price has long been underestimated not only influences the natural gas import, but also gives rise to overdevelopment of terminal consumption market, which seriously weakens the competitiveness in the natural gas industry and imposes great hidden dangers to the energy supply safety. As China's natural gas industry is developing towards the gas source diversification and pipe networking, the disadvantages of cost-plus method based on ex-factory price and pipeline transportation price have gradually become apparent. Since 2011, the net back pricing method has been put into trial use in Guangdong and Guangxi, and thus gate price is linked up with the price of alternative energy sources. As A Notice about Adjusting the Natural Gas Price was promulgated in 2013, the net back pricing method implemented in Guangdong and Guangxi was promoted throughout China. Therefore, the upstream exfactory price was no longer directly controlled by the government, the price control was shifted from ex-factory link to gate link, and the price was autonomously negotiated between the supplier and demander within the range of price ceiling. This was a breakthrough of natural gas price reform, which was of great significance for straightening out the price relation between natural gas and alternative energy sources and getting geared to the international level. However, obvious regional differences in natural gas consumption level are manifested across China, so the natural gas price will be elevated by a large margin if the net back pricing method is independently used and the supply-demand relationship is regulated by price, and consequently, areas with low natural gas consumption levels in China will have to bear high gas use cost.

\subsection{Current situation of natural gas market supervision}

In China, the natural gas regulators mainly include: National Development and Reform Commission (NDRC), National Energy Administration (NEA), Ministry of Finance, Ministry of Land and Resources, State-Owned Assets Supervision and Administration Commission, Ministry of Housing and Urban-Rural Development, etc., among which the Ministry of Land and Resources mainly manages the upstream exploration and development right (namely, mining right and exploration right) and related technical standards, and formulates relevant laws and regulations. NDRC is responsible for policy-making, price control and supervision, etc. NEA, which is subordinate to NDRC, is in charge of natural gas industry planning. The Ministry of Finance reviews the cost and benefit and stipulates the related taxes and dues, but it is the State Taxation Administration, but not the Ministry of Finance, that collects such taxes and dues. It is not difficult to see that lacking an independent natural gas regulator, the regulating functions are dispersed among various governmental sectors. However, the regulatory standard and regulatory agency, which integrates the independence, specialty, accountability system and consistency, constitute an essential path to standardize the enterprise operation, correct the market failure, and improve the natural gas market efficiency.

\section{Problems Existing in China's Natural Gas Price Reform}

\subsection{Problems in the natural gas industry chain}

The natural gas price reform involves all links in the industrial chain, including upstream exploration and development, midstream transportation, and downstream distribution and sales. The development of natural gas market was controlled by administrative means in early phase, which reduced the natural gas holding cost under unsound market, and as a result, the majority of mining right was held by CNPC, Sinopec and CNOOC, while other subjects, even with better conditions, had no access to mining right, and it was still difficult for them to enter the market. Affected by the expected price decisions and in pursuit of profit maximization, the companies will choose to develop natural gas only when the price is higher than the expected price, so many mining areas are idled, and the upstream exploration and development potentials cannot be fully exerted.

China has let loose the gas sources and attempted to cultivate upstream and downstream markets into highly competitive ones in recent years, but the social welfare and enterprise interests cannot be balanced because of the natural monopoly of the midstream industry. In the midstream link of China's natural gas industry chain, both natural gas output and consumption are increasing faster than the pipeline transportation mileage of natural gas, along with insufficient natural gas pipeline construction, incomplete infrastructure and serious reliance of pipeline construction on the three giant companies. On the other hand, review and approval procedures, which take a long time, are needed in order to enter the midstream link, so the difficulty for third-party subjects to gain access to the midstream link is aggravated. Therefore, the supply and marketing can be separated and the leverage effect of price can be fully released only by perfecting the supporting pipeline infrastructure and services in the midstream natural gas pipeline transportation link.

\subsection{Unreasonable natural gas pricing mechanism}

The net back pricing method was put into trial implementation in Guangdong and Guangxi in 2011, and then promoted throughout China. This pricing method has a high requirement for gate pricing, because the gate price will influence the subsequent pipeline transportation price, ex-factory price, and gas use price of end users.

Natural gas is imported into China mainly in two ways: liquefied natural gas importing by sea, and pipeline natural gas importing from Central Asia. The costs of natural gas imported by both means are higher than that of natural gas produced in China. In July, 2013, it was stipulated that natural gas produced in China and imported natural gas were both priced by gate pricing, so the profit gained by CNPC, the enterprise with the largest natural gas output and import volume, through domestic production and 
sales was not enough to offset the loss due to the sales of imported gas. At the time, the shortcomings of this stipulation were exposed.

The benchmark gate pricing formula for natural gas is not accurate enough in China. In comparison with the $\mathrm{S}$ curve used in the long-term contract on international trade of liquefied natural gas in the Asia-Pacific market, the straight-line form adopted in the benchmark gate pricing of natural gas in China has some certain defects. As shown in Table 1, compared with the $\mathrm{S}$ curve, the coefficient obtained by the straight-line formula is small under low crude oil price, which is hard to accept for upstream gas suppliers. On the contrary, the coefficient obtained by the straight-line formula is large under high crude oil price, which is hard to accept for downstream gas users.

Table 1: List of Benchmark Prices in Shanghai under Different Circumstances

\begin{tabular}{|c|c|c|}
\hline \multirow{2}{*}{$\begin{array}{c}\text { International crude } \\
\text { oil price/ } \\
\text { (USD· barrel - 1) }\end{array}$} & $\begin{array}{c}\text { Benchmark price in Shanghai/ } \\
\text { (RMB } \mathbf{~ m}^{\mathbf{3}} \text { ) }\end{array}$ \\
\cline { 2 - 3 } & $\begin{array}{c}\text { Straight-line } \\
\text { formula }\end{array}$ & S curve \\
\hline 40 & 1.36 & 1.92 \\
\hline 50 & 1.63 & 1.92 \\
\hline 60 & 1.9 & 2.13 \\
\hline 70 & 2.18 & 2.3 \\
\hline 80 & 2.45 & 2.45 \\
\hline 90 & 2.72 & 2.56 \\
\hline 100 & 2.99 & 2.64 \\
\hline 110 & 3.26 & 2.69 \\
\hline 120 & 3.53 & 2.69 \\
\hline
\end{tabular}

\subsection{Lack of effective market supervision}

China's natural gas industry has been regulated by integrating policy making and supervision for a long time. However, the supervisory force and balance mechanism still lag behind, because the policy-making departments are overlapped with supervisory authorities, without a clear delineation of functions, which may trigger repeated setting of supervisory authorities and waste of resources. On the other hand, the supervisory authorities appear not to coincide in opinions, it is difficult to handle the contradictions among them, so the coordination capability is poor, and moreover, the governmental regulatory functions are weakened, dispersed, overlapped or omitted, as there lacks a centralized administrative department, and few professionals are employed in supervision departments. Relative to other countries with sound natural gas market development, the natural gas supervisory authorities are mostly associated with the government in China, and their financial expenditures are supported by the government. Furthermore, the government regulation is not clearly differentiated from the enterprise supervision in China's natural gas market. As the three giant petroleum companies, which play a decisive role in China's natural gas market, will sometimes participate in the formulation of market planning with government sectors, which seems unfair for the competitors within the same industry.

\section{Suggestions on China's Natural Gas Price Reform}

\subsection{Accelerate and perfect the policy of "controlling the middle and loosening the two sides", and realize business separation and third-party access}

Only a reasonable industrial chain can effectively exert the regulatory effect on the price. The general thought followed in China's natural gas price reform is "letting loose the two sides, controlling the middle, introducing the competition, and implementing moderate supervision". "Letting loose the two sides" means loosening upstream gas sources and downstream sales and strengthening the supervision and management. To be more specific, the government provides private capitals and foreign capitals with preferential policies, tax preferences and subsidies, accelerates the establishment of mining right transfer system, and transforms the registration system into a bidding mode that contributes to effective competition, thus providing other subjects with the access to the market The Chinese government can support enterprises intended to enter the natural gas market by formulating related systems and subsidy policies, so as to strengthen the market competitiveness and weaken the market monopoly. "Controlling the middle" focuses on controlling the midstream pipeline transportation cost and fixed rate of return, accelerating the implementation of the third-party access policy, giving the opportunity to other capitals to enter the midstream link and accelerate their pipeline construction, enhancing the fairness and openness of pipe network, building a pipe network information disclosure platform, and preventing pipe network companies from monopolistic behaviors. Secondly, necessary subsidy policies can be implemented for the enterprises intended to enter the natural gas market. While guaranteeing the qualifications, the government can simplify the review and approval procedures to facilitate the natural gas infrastructure construction in China as soon as possible.

\subsection{Loosen the gate price of imported natural gas}

With the advancement of oil and gas system reform, the pattern of "supply exceeding demand" has been formed in the global natural gas market, so the gate price will be gradually taken just for reference instead of exerting the governmental guiding effect. In recent years, China has loosened the trade platforms of offshore gas, shale gas and coal seam gas in succession, so the open trade of gas is formed in the market, and only domestic onshore pipeline natural gas and imported pipeline gas are still regulated by the government. As the marketization of natural gas forges ahead, it will be the best choice to let go of natural gas gate price. In consideration of unbalanced economic development between western China and eastern China, domestic gas can be used in western regions and also eastern regions self-sufficient in natural gas, which exerts a certain buffering effect on the economy of western underdeveloped regions, while imported gas is a choice for eastern regions, which are economically developed. 
This can not only mitigate the loss caused to import enterprises and further marketizes the gate price, but also can effectively solve the gas use problem induced by the unbalanced economic development between eastern and western regions.

The $\mathrm{S}$ curve used in the long-term contract on international trade of liquefied natural gas in the AsiaPacific market may be the optimal solution to the conversion coefficient in the benchmark natural gas gate pricing formula. The conversion coefficient obtained by the $\mathrm{S}$ curve is large under low crude oil price, while that under high crude oil price is small. Compared with the straight-line formula, the $\mathrm{S}$ curve is fairer for both upstream and downstream users, the obtained benchmark gate price is more reasonable, and moreover, it can effectively accelerate the price marketization.

\subsection{Establish a unified, independent and professional supervision system}

A reasonable natural gas supervision system plays a significant role in the marketization of natural gas. From the central level, a unified professional management organization should be established to get rid of separate managerial supervision in each sector. This national-level management organization must be independent, namely, it should be associated with neither the government nor natural gas enterprises. From local level, the central management organization should strengthen the supervision of incomplete aspects in some local-level supervision organizations, and make efforts to perfect local-level supervision as soon as possible, while not having any subordinate supervisory organization. The central supervision organization should regularly supervise the local-level organizations, and timely correct the management mistakes or mistakes in other aspects. Meanwhile, natural gas professionals should be cultivated to conduct natural gas technology R \& D, management, etc., and supervise the various links of the natural gas industry chain, pricing mechanism and price management, thus accelerating the marketization of natural gas in China.

\section{Conclusion}

The healthy development of natural gas industry in a country depends on its pricing policy to a great extent, while the natural gas pricing mechanism reform is a complicated system engineering. By analyzing the current situation of China's natural gas industry chain, natural gas price and natural gas regulation and the existing problems, it has been pointed out that the general thought in China's natural gas price reform is "letting loose the two sides, controlling the middle, introducing the competition, and implementing moderate supervision". The suggestions are proposed as follows: improve the unreasonable factors in the natural gas pricing mechanism, and establish a unified, independent and professional regulatory system, in an effort to finally realize the marketization of natural gas price.

\section{Acknowledgments}

This paper is one of the phased achievements of the research project "Process Oriented and Task Driven Scenario Simulation Teaching Mode - Taking the Course Reform of Financial Service Etiquette as an Example" of the education and teaching reform in $\mathrm{Xi}^{\prime}$ an Mingde Institute of Technology.

\section{References:}

1. Sergey Paltsev, Zhang D W. Natural gas pricing reform in China: Getting closer to a market system? [J]. Energy Policy,2015,86.

2. Zhang Y, He C L. Straighten out the price of natural gas industry chain by taking the opportunity of pipe network reform [J]. Natural Gas Technology and Economy, 2019, 13 (05): 1-6.

3. Aviral Kumar Tiwari, Zinnia Mukherjee, Rangan Gupta, Mehmet Balcilar. A wavelet analysis of the relationship between oil and natural gas prices [J]. Resources Policy, 2019, 60.

4. Chen B. Influence study of China's natural gas price reform on the development of urban gas industry [D]. Dongbei University of Finance and Economics, 2018.

5. Lin L. Study of China's natural gas reform and its impacts [D]. Xiamen University, 2014.

6. Zhao H. The current situation of China's natural gas price revolution and suggestions [D]. China University of Petroleum (Beijing), 2017. 